\title{
Contrasting Industrial Decline through "Place-brand" Strategy: Notes and reflections on civic activism of entrepreneurs in Italy
}

\author{
Dipak R. Pant \\ Università Carlo Cattaneo (Liuc)
}

These notes are based on the experiences of taking an anthropological approach to help the management of business organizations in northern Italy. Anthropology is actor (human)-centred and context (socio-ecological complex)-focused. Its approach to improving business performance tends to raise the actors' awareness of their own contexts, not only at the micro-level (organization, stakeholders, market segment) but also at the macro-level (community, place-system). An anthropologist's help in management is basically about raising business actors' awareness and sustaining their efforts in adding value to their organizational assets and resources, as well as in improving the quality of their operational context. The anthropological difference rests with a holistic perspective and a long-range view to enhance the value of products/services of the workplace and human resources, of the business process, and of the entire context where the business is going on (place-system, community).

\section{Theoretical Premise: Anthropology in the World of Business}

Anthropology is actor (human)-centred and context (socio-ecological complex)-focused. Its approach to any human and societal phenomenon, including those pertaining to the business world, is to conduct in-depth contextual analysis of the reality to learn from the past (hindsight) and to logically exercise foresight. It is far more comprehensive (holistic) as compared to the approach of conventional economics, business studies or management discipline. The anthropological difference rests with a holistic perspective and a long-range view in contrast to the compartmentalized (specialized) vision and short-term orientation of conventional economics, business or management studies. In the past three/four decades, a few anthropologists have taken initiatives to help business and management studies. According to some of the well-known exponents of Business Anthropology in the USA, a wide variety of contemporary business problems can be tackled with the help of anthropological tools (Baba, 1986; Jordan, 1994 \& 2012). Anthropology was not applied seriously in the business world until the 1980s. Except for a few sporadic cases of individual application (workplace ethnography) in some business organizations, no systematic anthropological inquiry into business realities was previously conducted. In the early 1980s, in the USA, "organization" became a subject of great interest to anthropologists; "culture" to the experts of business and administrative studies; and "organizational culture" to the both (Marrewijk, 2010). From the 1990s up to today, Anthropology has been making great strides in studying the cultural aspects of the business world and in formulating answers to a number of management challenges in the USA and elsewhere. 
Anthropology is the most "scientific" among all humanistic disciplines for its sound footing on empirical grounds. At the same time, it is also the most "humanistic" of all the sciences for its central concern for the human being. Anthropology is quintessentially interdisciplinary. It is capable of bridging the distance that separates societal, economic and biophysical information, and may integrate and explain diverse types of data and information to produce a more coherent picture in a holistic perspective. An anthropological perspective helps to find sustainable solutions to contemporary human problems (Bodley, 2008) because anthropology deals with all the three dimensions of human existence: being (i.e. the manifested realty of human existence and endeavour), becoming (i.e. the evolutionary patterns), and knowing (i.e. substantial contents of the traditions such as native know-how, weltanschauung, morals and manners, explicit codes and modes...). The third dimension - "human knowing" — has not been sufficiently explored yet. There has always been a subtle ethnocentric (Euro-centric) paradigm in the modern anthropology which was entirely Western initially. It still continues to be dominated by the modern Western cultural paradigm and an urban-based cosmopolitan world-view. Until recently, most anthropologists did not care to learn from the people, but only to know about them, and to explain this knowledge in their own civilization's (and their historical period's) terms and propositions. With increasing contributions from non-Western anthropologists and with the emergence of a new generation of scholars and practitioners everywhere, the situation has somewhat changed. Traditions are being taken seriously as possible sources of scientific hypotheses. The contents of many traditions are receiving robust attention as sub-disciplines and fields of research. Similarly, the business practices and management models of different cultural contexts are also receiving attention. The business world has already become a new field of anthropological inquiry.

The application of anthropology to business and economic issues is relatively recent, and is expanding. This is largely due to two new interrelated developments.

First, there has been a tectonic shift in the very subject-matter of anthropological study in recent decades. The so called "primitives" are too few; many have already been acculturated, and over-studied. Most of the traditional (mostly non-Western) contexts are undergoing rapid transition. And modern industrialized societies (i.e. Western ones) are proving to be much more "exotic" and under-explored than they were generally supposed to be.

Second, in the past decades, totally new business landscapes have emerged almost everywhere in the world. The global presence of multinational companies (i.e. a single enterprise engaged in different geo-cultural contexts), an increase in workforce diversity (i.e. persons of diverse geo-cultural origins within a single enterprise), the spread of industrialization in non-Western societies, and many far-reaching technological innovations have created complex situations. All of these are beyond the reach of conventional economics, business studies and management disciplines. These new conditions have opened ample space for anthropologists to participate in the study of business world.

At present, the globalization of business is creating unprecedented situations involving a diversity and multitude of personalities, generations, political and administrative systems, legal frameworks, organizations, communities and cultures. It means that there are new opportunities to observe, analyze and interpret human dynamics in different circumstances. Companies operating in different cultural contexts and business units having workers with different educational and ethnic backgrounds are facing serious difficulties in creating a coherent organizational culture (Schultz, 1995). The current pace of global interdependence, technical innovation and world-wide competition is forcing business leaders to constantly rethink their strategies based on long-established thinking and practices. Today's business dealings are across the boundaries of political systems and cultural contexts. The human components (from suppliers to consumers) and the material components (raw materials, manufacturing plants, after-sales service apparatus, recycled materials, waste, etc.) are multi-local and multi-cultural. Today's businesses involve materials, skills, resources (both raw and recycled matter) and organizations from diverse environments and socio-cultural contexts. This implies that there is interplay of more than one culture, even in a single business process. The administrative, legal and financial environments of different countries are already 
difficult to grasp despite being usually well-codified, translatable, communicable and comprehensible. The chances for error and misunderstanding are always there although being relatively low, whereas, the risk of error and misunderstanding about the cultural context is quite high because they are not well codified, and are quite intangible and extremely difficult to grasp, translate and communicate. Serious management mistakes leading to business failure have been attributed to the lack of proper understanding of the cultural contexts (Ricks, 1983). The grasping of cultural context is essential in international business in order to avoid mistakes and problems (El Kahal, 1994) as "culture", the basic blueprint of individual and collective behaviour, constitutes the permanent backdrop of all the other legal, political and financial developments.

Studying human habitats, cultures, communities, economic systems and organizations is learning from the people and not merely knowing about them. It is, fundamentally, approaching the actors of a given context, understanding their context (habitat and community), their roles and functions, their perception and ethos. Above all, it is important to learn their values and practices not as dogmatic ideas or exotic curiosities but as their context-specific functional elements. Knowledge and customs of even the most backward human groups constitute readily available sources of scientific hypotheses. Human traditions all over the world provide plenty of locally practiced solutions that can serve as hypotheses to examine the problems and to verify the functionality and sustainability of the solutions offered and, eventually, to explore the applicability of those solutions in other contexts. For example, many precious lessons can be learned about human survival, adaptation, human-environment relations and sustainability strategies from the traditions of the communities historically inhabiting the extreme lands (highlands, tundra, taiga, steppes, desert, savannah, jungle, etc.). Such lessons can help us in remodelling economic and environmental policies and in drawing efficacious development plans. As another example, the lessons we can learn about Italy's small and medium entrepreneurs and their deep attachment to their territorial and communitarian roots, their "business-place-community" nexus. Such lessons are helpful in the search for new strategies to manage the difficulties, to sustain the social progress, and to avert economic and civic decline.

\section{Practical Experience: Learning to Serve and Serving to Learn in the Italian Business World}

For more than two decades, my other job (outside the university) has been to provide advisory services in strategic planning and general management, in training and coaching the senior executives of industrial and commercial organizations, as well as to help officials from public agencies and non-governmental organisms in Italy and abroad. This other job has provided opportunities for surveying many different human habitats, socio-cultural contexts and economic organizations; a good part of that being in Italy. Serving in an advisory role to Italy's entrepreneurs, managers and administrators has been a great learning opportunity about manufacturing industries, industrial districts, development projects, business operations, and market realities. As a scholar and practitioner of anthropology, I have tried to contextualize the economic lessons learned inside a broad frame of habitat, community, traditions and institutions. Such contextualization is directly related to the human-centred and holistic perspective derived from anthropology which, I believe, may help to identify sustainable strategies to cope with industrial decline in some localities of Italy.

Italy is relatively a small country with a little more than $300,000 \mathrm{sq} . \mathrm{km}$. of total area comprising some big and small islands, and with a total population of around 60 million. It is a narrow peninsula protruding southward into the Mediterranean, and capped by the Alps mountain range along the entire northern frontiers (bordering France, Switzerland, Austria and Slovenia). Most of Italy is a rugged earthquake-prone and hydro-geologically unstable surface, a relatively tough terrain. Almost two-thirds are covered by hills and mountains; fertile flatlands and coastal lowlands constitute the rest. Building and maintaining large-scale industrial infrastructures in Italy has always been a challenging task. 


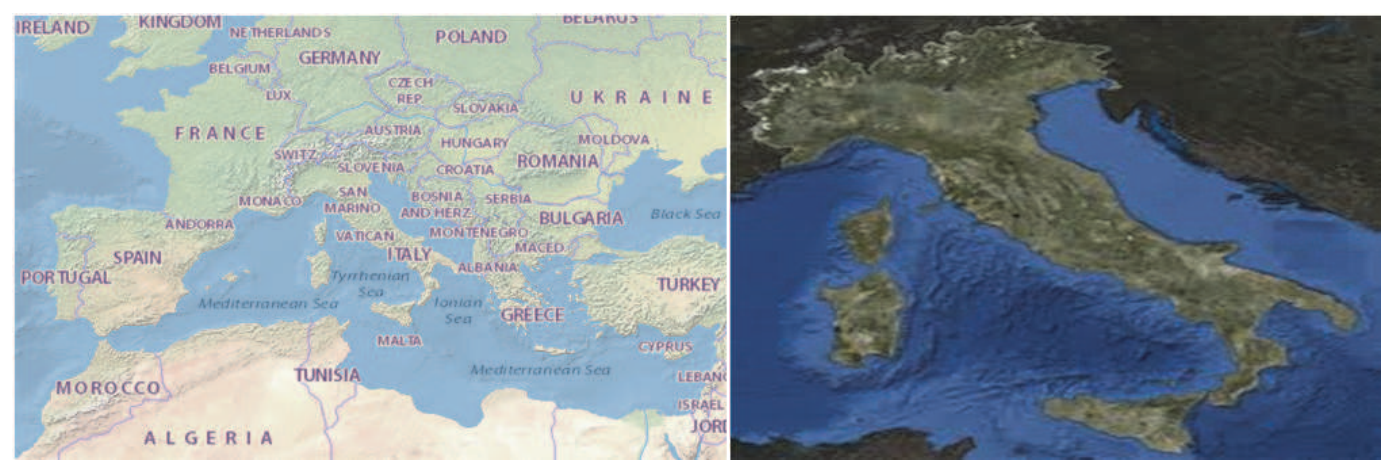

Among all wealthy nations in the world, Italy is by far the poorest in terms of underground and off-shore resources such as minerals, forests, agricultural land, coal, oil and gas, etc. Historically, Italy's access to cheap raw material outside Europe has been quite limited owing to its negligible colonial activities in the past unlike the UK and France who colonized many countries and had unhindered access to resources and markets in many continents (they are still enjoying privileged commercial links with former colonies in many cases). Despite lack of natural resources at home and without significantly rich colonial possessions abroad, Italy excelled in industrial activities and became one of the wealthiest nations in the world, being among the three top manufacturing nations in the European Union (along with Germany and France) and among the eight largest industrial producers in the world (including the non-European nations: USA, China, Japan, Korea and India). Italy's industrial performance can be explained only by contextualizing it in a broader perspective that includes human resources (craftsmanship, skills) and cultural peculiarities. Italy's rich "over-ground" and non-material resources are: human capital, a tradition of arts and crafts, the Italians' ethos, and a great variety of regional and local specialties and local skills (genius loci). Italy's "over-ground" and non-material resources have compensated for the scarcity of under-ground and off-shore material resources (i.e. lack of minerals, coal, oil and gas, etc.), which has determined Italian industrial success.

A process of de-industrialization seems to have crept into Italy in the late twentieth and early twenty-first centuries (Accetturo, Giunta \& Rossi, 2011). Italian industries are facing a number of difficulties and daunting challenges posed by fierce global competition, a heavy tax burden, an aging workforce, a credit crunch related to the volatility of the global financial markets and indebtedness of local banks, a decline in consumer confidence, and a deepening recession in the economy. For the foreseeable future, it seems unlikely that the Italian government can introduce significant fiscal incentives and enough cheap credit to help the ailing industrial sectors. Neither can the government reduce the current level of tax pressure on Italy's corporate nor on individual tax-payers because of the country's enormous sovereign debt. Despite the excellence of its products, Italy's overall business competitiveness is quite low compared to other Western economic systems. It is expensive and burdensome to start and to run a business in Italy. Italian business organizations rightly complain about tax pressures, high tariffs paid for utilities and facilities, and the aging infrastructure (and, to some extent, also about corruption ${ }^{1}$ ). The capacity of Italian entrepreneurs to make long-term decisions is weakened by the persistent climate of political instability at the national level and, to some extent, also by the recent crisis of confidence in the common European currency (the Euro). The business-friendliness of policy-making organs and civil bureaucracy seems to be a burning issue for Italian firms. Italian entrepreneurs complain about the level of interference, overlapping and complex regulations, and about the administrative inefficiency of Italy's institutions. International observers tend to substantiate Italian entrepreneurs' complaints. Despite being one of the top industrialized and wealthy nations in the world, Italy's overall competitiveness is quite low, being ranked 44th in global competitiveness among 138 national economies. From the specific standpoint of public institutions (policies, norms, governance, and bureaucracy), Italy's competitiveness score is even worse: 103rd among 
138 national economic systems examined by the experts of the World Economic Forum (Schwab et al., 2016). ${ }^{2}$

Italy's Manufacturing Industrial Activity Index 1990-2015

$(100=$ full capacity normal production $)$

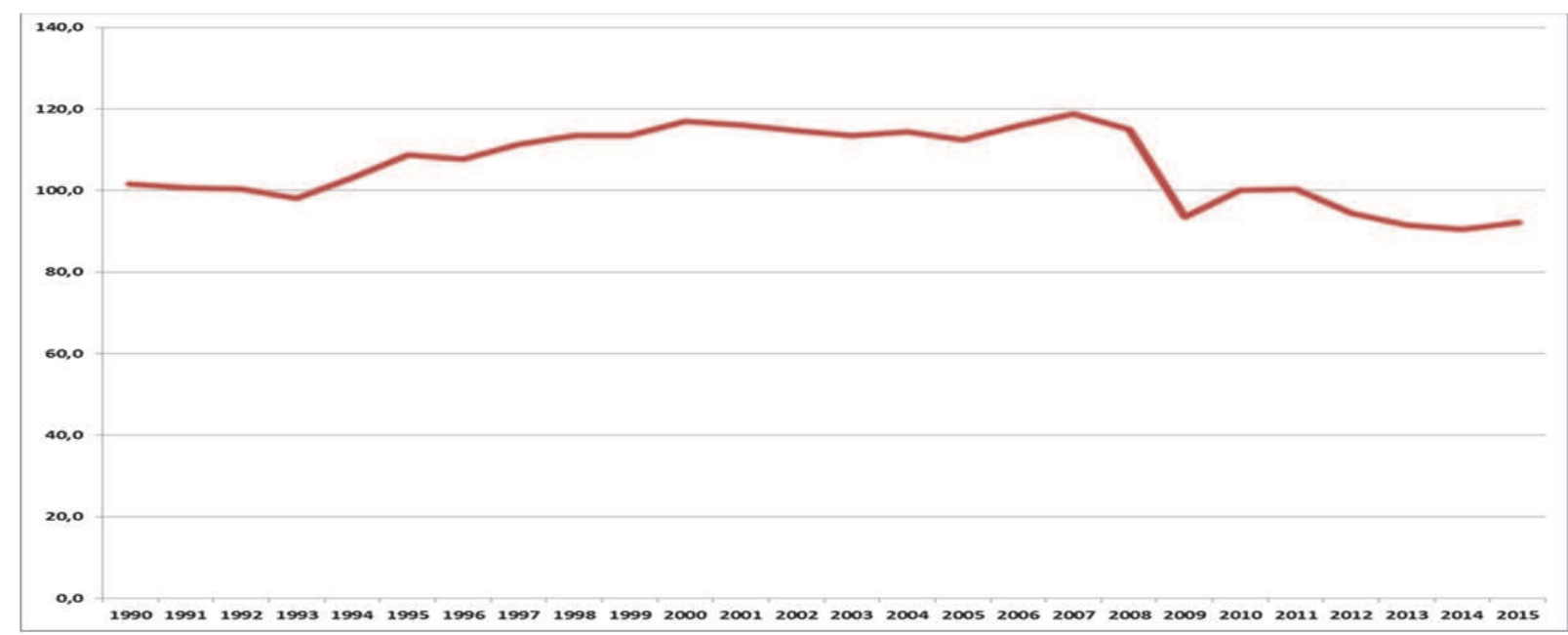

Source: ISTAT, 2016

Italian industry is well known for quality, durability and aesthetic appeal of its goods. Lately, the Italian manufacturing sector, where family-owned and family-run businesses are concentrated, has begun to suffer an inexorable decline (Paolazzi \& Traù, 2012). Some large and medium corporations have moved to cheaper labour markets abroad, reducing parts of the country to industrial wastelands and alienating the manpower from the socio-economic mainstream. ${ }^{3}$ Italy's industrial decline has been aggravated by the constant appreciation of the Euro. The Euro's high value inhibits Italian exports. Italy's government and central bank can no longer manoeuvre monetary policy (i.e. "manipulate" the currency) to help Italian exporters, because the Euro is governed by the European Central Bank following a particular set of fiscal policies cooked up by an inter-governmental mechanism that leaves no space for autonomous national monetary policy for the member-states who have joined the common currency. Besides the issues of monetary policy, Italian exporters have been facing difficulties from the waves of economic recession in rich Western markets, the usual destination of high-quality and expensive Italian products manufactured by small-scale, family-run companies that emphasize tradition and quality. Italian industrial products do not end up in the mass market of middle- and low-income countries. Italian products are high quality, but are unable to compete on price with similar items produced on a larger scale by transnational corporations whose managers are global corporate professionals and whose operational units are located in the world's low-cost zones. Although a few Italian industrial firms have internationalized their production, moving the operational units to low-cost contexts is very difficult for the Italian industrial organizations because of three peculiarities: small size, family ownership (impresa familiare) and local roots (territorialità = "business-place-community" nexus).

More than 90 per cent of Italy's approximately six million businesses are owned and operated by families, most of whom have 50 or fewer employees. Even among the medium and large Italian corporations, around 40 per cent are owned by families whose members are active in management (Movimprese, 2012; Paolazzi and Traù, 2012). More than half of family firms are actively headed by a senior family member around or above 60 years of age. Every year, tens of thousands of family businesses undergo an inter-generational management transition, a critical phase in a family firm's life. Around half of 
all family firms, particularly the small ones, cease to operate as an independent business entity in the third generation; only 15 per cent of family firms continue to operate beyond the third generation (Cicogna and Devecchi, 2007).

A salient feature of Italy's industrial localities (distrettiindustriali) is the central role of human relations (family, kinship and friendship). That is why Italian business-persons are crucial stakeholders in the local cultural identity and for the prestige of their place-system. They are under constant social scrutiny, and they bear great social responsibility because of their place-based identity. The social legitimacy of Italian businesses is based upon their role in maintaining their presence in their native place, in continuing the tradition of community and family values, and in taking care of local culture and social cohesion. The social legitimacy of Italian firms is eroded in cases of massive relocation of business activities outside their own place, or any sell-out of the business to outsiders. Even large Italian corporations tend to maintain some part of their industrial activities in their original native place due to their attachment to native habitat and community and owing to their concern for social legitimacy.

\section{Terra di Cuore: Place-Brand Strategy for Sustainable Prosperity}

The lessons learned from Italian business practice guided me to a hypothesis that industrial decline can be countered and that widespread sustainable prosperity may be achievable if there is an acute awareness of the critical nexus between business success and continuity with the "quality of context" (the quality of place-system). A context of quality denotes a place-system that is liveable, visit-worthy and investment-worthy (vivibilità-visitabilità-investibilità). The family firms with their territorial identity and community ties may have a unique sensibility and capacity to push for the quality of their organization as well as of their context (Denison, Lief \& Ward, 2004). Based on the three most prominent features of Italian industrial landscape - family business, small/medium size, and the sense of belonging to the native place and local community - I have proposed a few ideas to counter the economic depression in different localities of Italy. The proposal is about a collaborative campaign (civic activism) led by local entrepreneurs in order to enhance the "quality of context" of their locality. The idea has been termed as the "campaign for Terra di Cuore".

Terra di cuore literally means "land of the heart". A proper translation would be "place that is in your heart" or "the place where your heart dances". It is an idea that local business leaders can reach out through a concerted civic campaign to uphold shared values and measurable (and enforceable) environmental and social-quality standards in their work-place and in their native place (community site, locality). Italian entrepreneurs have been successful in injecting a high quality of design into their products and services. The material micro-designs of products made in Italy are globally recognized for their excellence. But, the civic macro-design, the place-system, is not as much satisfactory. Italy's town planning, mobility system, new buildings, waste management and public space up-keeping are far below the standard displayed in the micro-design. It seems a paradox: excellence in micro-design, low quality of macro-design. It, therefore, seems reasonable to mobilize the awareness of local entrepreneurs about their place-system's macro-design ("quality of context") and to channel a part of their resources in improving the civic macro-design of their native context where they live, work and interact-their Terra di Cuore. The idea of Terra di Cuore was being tested in some localities of Italy ${ }^{4}$ with intellectual support from my team of collaborators.

The basic idea is to focus on the "quality of context" as much as on the quality of products and services. The entrepreneurs' activism for "quality of context" enables the business community to have a better dialogue and positive cooperation with public institutions. It makes it easier to obtain moral legitimacy and social consensus for business. Workforce productivity and workers' loyalty are likely to benefit from the efforts for "quality of context". "Quality of context" efforts (the process itself) may help to foster business diversity, and attract investments and touristic visits. The effort/process to achieve the "quality of context"

helps to construct wider social cooperation and to project a distinct place-brand. ${ }^{5}$ Once promoted, the place-brand of a locality provides a competitive edge to all local actors in business and professions. Terra di Cuore is actually a place-branding and territorial marketing campaign led by the entrepreneurs themselves. 
It is based on shared values and measurable (and enforceable) social and environmental quality standards. It may help to retain and develop local resources, to foster trade, to diversify local business, to attract new investments, to protect local cultural heritage, to safeguard the environment and beautify of the landscapes, and to develop tourism. Even without much gain in trade and tourism, it certainly mobilizes local resources and public opinion towards sustainability and wellness, legitimizes the business-persons, and enhances collective well-being and social cohesion. In the matured (and saturated) industrial contexts of Italy, I believe that economic decline can be contrasted that local entrepreneurship may be diversified and developed, and that a sustainable prosperity (long-term economic security) is achievable. For this, I believe that business-persons must be encouraged to come forward to improve the quality of their context, and to construct and promote their place-brand.

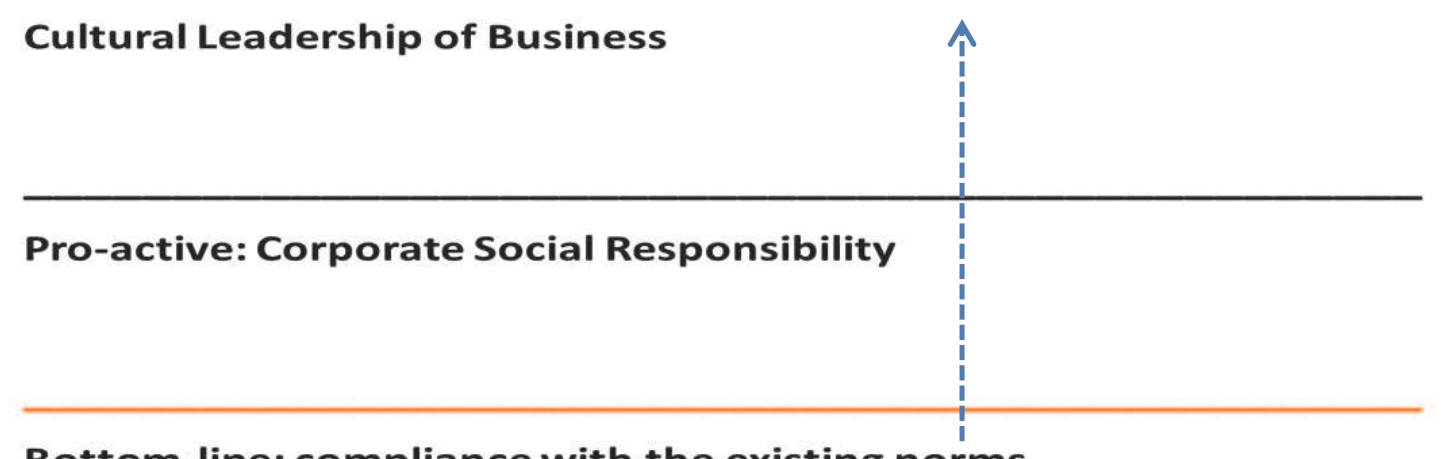

Bottom-line: compliance with the existing norms

The idea of inclusive and encompassing progression in entrepreneurial action-from a family-owned business-system to a community-shared place-system - is actually a model of cultural leadership for Italy's entrepreneurs. Cultural activism of entrepreneurs is much more than "corporate social responsibility" (CSR). CSR is about pro-active measures to improve social and environmental impact of business by going further (better) than the normative prescription. Certainly, it is a superior proposition compared to the simple law-abiding (i.e. compliance with existing norms) which is the lowest axis and the bottom-line of sustainability. Much above the passive basic compliance and beyond the active CSR, the cultural activism of entrepreneurs is an exercise of a civic role at the highest level.

\section{Lessons Learned by Helping the Entrepreneurs to Help Themselves}

The civic activism of some Italian entrepreneurs in their locality is a long-term and open-ended proposition. In the long run, many programmes can be launched and a variety of specific projects may be implemented. Anthropological skills and perspectives are helpful in the following fundamental groundwork:

- Mapping local values (la mappadeivalori): identifying and assessing the specialties of the place, particular skills of the local people (genius loci) and environmental and cultural resources; there is a big role for ethnography, archaeology, human ecology and geographical information system (GIS) in this regard;

- Mapping local vulnerability (la mappadei dis-valori): critical situations in habitat, business, human capital and social security; ecological, ethnographic and sociological survey can be integrated with geographical information system (GIS) and other technical disciplines (e.g. civil and structural engineering) for this work; 
- Elaborating images of a local future through a collaborative foresight exercise to identify the best plausible image (the "scenario of reference"); and drawing a pragmatic and locally manageable roadmap that tends to be the best plausible alternative image of future, the "scenario of reference".

The third groundwork - collaborative foresight exercise - is the climax of all preliminary inquiries and field surveys. Collaborative foresight is exercised after collecting data/information and conducting field surveys. This exercise helps to explicate the images (more than one) of the future from the stakeholders themselves, by nudging them to think in the longer term about their place, community, activities and organizations. The stakeholders find it easier to articulate their vision once they participate in a careful analysis of the findings of preliminary inquiries and field surveys. A collaborative foresight exercise helps the entrepreneurs and executives to realize the importance of a long-range planning perspective. It also makes them acutely aware of the inner and intangible resources such as core values, identity, memory, distinction, prestige and relationships.

The most interesting outcome of collaborative foresight exercises has been in finding a unique correlation between an orientation to "sustainability" and time-scale. The longer the time-scale of foresight, the more sustainability-oriented thinking was expressed by the participants. When the entrepreneurs and executives stretched their imagination further ahead, after having taken into consideration the "values" and "vulnerabilities" of their place-system, they became acutely aware of the inseparability of the four aspects of sustainability:

- Economic-financial viability (profitability) of business activities and organizations;

- Healthy, happy, skillful, loyal and reliable operators in the workplace (human capital) who enjoy security and civic bond in the community;

- Good stock (quantity) and purity (quality) of the available environmental resources (e.g. air, water, soil, etc.) in the place-system, and the aesthetic quality of the natural and artificial (built) environment of the locality;

- Ethical approval and moral support from all concerned: family members, kinship and friendship networks, collaborators, all other stakeholders, institutions, and community at large.

Long-term economic-financial value (durable profitability) depends on the integrity and healthfulness of the habitat where the business is located. It also depends on the maintenance of human capital, security and social cohesion of the community with which the business is injected. Besides, businesses can't expect to receive the work-force's loyalty and the community's benevolence if their actions are perceived as indifferent or hostile to society and the environment. Social legitimacy is another key element in long-term, economic-financial value creation. Ultimately, what we learn about "sustainability" is that it is a composite and complex issue with four dimensions. 


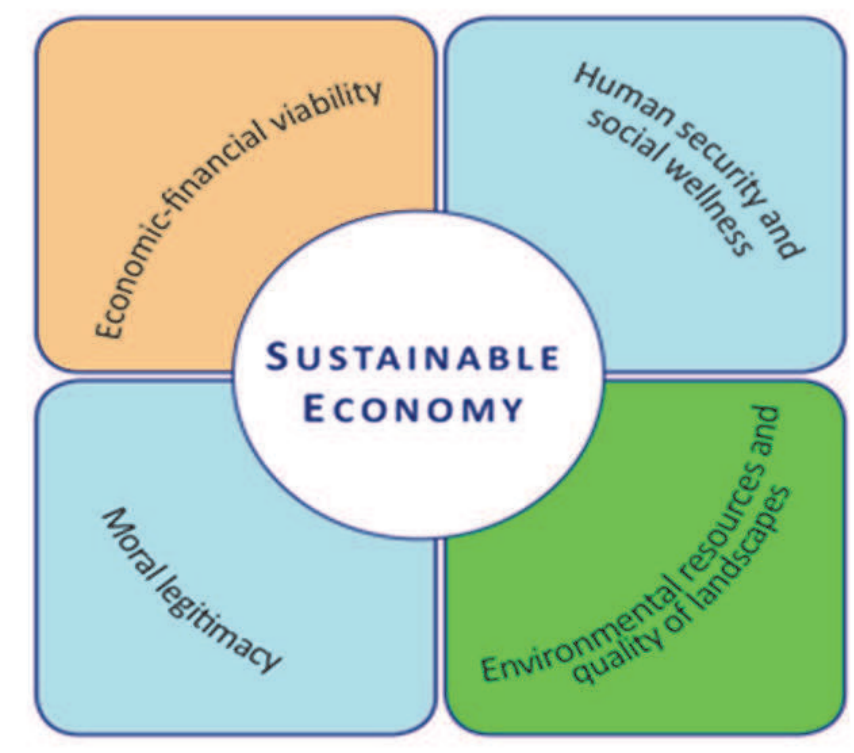

The four dimensions of "sustainability" are dynamically inter-related. Profitability makes financial resources available for investment in human capital and in environmental care. Improvements in the human capital and in the quality of habitat in turn improve productivity, reinforce the intangible assets (brand, prestige), and garner ethical approval and moral support.

\section{REMARKS}

It is too early to make any conclusion about the Terra di Cuore campaign. A few timid steps are being taken by business guilds and consortia in a couple of industrial districts in Italy. It may take a long time to measure the impact of civic activism by local entrepreneurs in improving the quality of their contexts. So far, they have been aided in contextual analysis, a method of mapping "values" and "vulnerabilities"; and, above all, they have been familiarized with the anthropological perspective.

The anthropological perspective is the strategic perspective par excellence. The anthropological perspective is gained through a thorough exploration of the recurrent patterns and implicit meanings underlying human habitats, communities, ethos, organizations and businesses. The comprehension of patterns and meanings leads us, logically, to a vision (scenario of reference) and to a particular course of action (roadmap) to make that vision become a reality. Anthropology is no doubt the treasure-trove of strategy. When applied to improving business or local economic development, anthropological knowledge and perspectives are ultimately helpful in transforming local efforts into the drive for "sustainability" in the holistic sense. In other words, it is the drive for an optimal mediation among habitat integrity, human wellness, social security, economic-financial viability, and moral legitimacy of the business activities and organizations. Anthropology can produce business strategies that have an ethical balance, achieved by aligning the collective drive for sustainability with the legitimate drive for profitability (business vitality and continuity). The alignment of profitability with sustainability helps to favour the well-being of the community, including entrepreneurs and workers (and their families), and to foster the integrity of local habitats, including workplaces and public spaces.

Sustainability is the ultimate ethical value for the application of anthropological knowledge. Application must be in the search for solutions that are long-term, most durable, most economically viable and morally acceptable. Sustainability is inherently a human-centred concept that carries the fundamental challenge of satisfying human needs of both present and future. 


\section{ENDNOTES}

1. According to a 2016 report of Transparency International (international public interest research NGO, based in Berlin, Germany), Italy ranks 60th in the "corruption perception index" among the 176 countries examined, and is perceived as one of the most corrupt in Europe.

2. According to the World Economic Forum, Italy's overall competitiveness in 2016 was lower than the majority of national economic systems in the European Union such as The Netherlands (the most competitive in EU, globally the 4th), Germany, Sweden, the UK, Finland, Denmark, Belgium, Austria, Luxembourg, France, Ireland, Estonia, the Czech Republic, Spain, Lithuania, Poland and Malta. Italy is even ranked below the emerging newly industrialized economic systems of Malaysia, the Republic of Korea, China, India and Indonesia. Switzerland is ranked as the most competitive economic system; the least competitive is considered to be Yemen (World Economic Forum, 2016).

3. The situation of young people aged 15 to 29 who are not in education, employment or training (NEET) in Italy was reported to be one of the worst among the 27 EU member states (ISTAT 2012); currently, Italy's unemployment is around $11.6 \%$ (ISTAT, 2016).

4. Between 2010 and 2016, conferences and workshops were held in several towns to discuss the idea. In 2013, a civic consortium of entrepreneurs called Prospettiva Casentino was established in the valley of Casentino (Tuscany) to collaborate with non-business entities for local development. The industrial association of Brescia (Associazione Industriale Bresciana) has formalized it as BRESCIA Più, a project of collaboration with other non-business entities of the province of Brescia (Lombardy).

5. The discovery of the "place-brand" concept was an unintended consequence of a field survey (late 1999) in and around Armenia's archaeological sites in order to explore proper ways of integrating the restoration of historical monuments with broader local (rural) development strategy; the mission was commissioned by an Italian non-governmental organization (Centro Studi e Documentazionesulla Cultura Armena, Venice) in collaboration with Armenia's National Board for the Restoration of Historical Monuments (Ministry of Culture, Yerevan). I coined the term "place-brand" and suggested it as an economic strategy for Armenia's government in a published report in 2000. In that case, my argument was that the socio-environmental requalification of the "place system" would lead to a global marketing strategy to replace the common international perception of Armenia as a remote and trouble-prone ex-Soviet land by highlighting Armenia's heritage, landscape, typical products and lifestyle; and that would attract qualified investments and develop tourism. Following the Armenia work, I was invited to join a group of scholars and practitioners of various disciplines to launch and serve as editorial board member of a new international journal called Place Branding \& Public Diplomacy, being published since 2004 (initially by Henry Stewart UK, and later by Palgrave Macmillan UK). 


\section{REFERENCES}

Accetturo, A., Giunta, A. \& Rossi, S. 2011. "Le imprese italiane tra crisi e nuova globalizzazione." L'INDUSTRIA, XXXII, 1: 145-163.

Baba, M.L. 1986. "Business and Industrial Anthropology: An Overview." NAPA B ULLETIN, Vol. 2, Issue 1, American Anthropological Association, USA.

Bodley, J.H. 2008. Anthropology and Contemporary Human Problems, Altamira Press (Rowman \& Littlefield Publishers), Lanham/New York (USA), $5^{\text {th }}$ edition.

Cicogna, A. \& C. Devecchi. 2007. "L'impresa familiare italiana: una specie da proteggere." Ch ALLENGE 2000 (La rivista di Management per l'Azienda Evolutiva, Data Consult Group Srl) 23:36-43.

Denison, D., Lief C. \& Ward, J.L 2004. "Culture in Family-Owned Enterprises: Recognizing and Leveraging Unique Strengths." FAMILY BUSINESS REVIEW, 17(1):61-70.

ISTAT. 2016. Annuario Statistico Italiano 2016. Rome: Istituto Nazionaledi Statistica (national bureau of statistics), Rome (Italy).

Jordan, A.T. 2012. Business Anthropology, Waveland Press, long Grove (Ill.), USA.

Jordan, A.T. 1994. "Organizational Culture: The Anthropological Approach." NAPA BULLETIN, Vol. 14, No. 1, American Anthropological Association, USA.

El Kahal, S. 1994. Introduction to International Business. London, McGraw-Hill International (UK).

Marrewijk, A.V. 2010. "European Developments in Business Anthropology." INTERNATIONAL JOURNAL OF BUSINESS ANTHROPOLOGY, Vol 1 (1): 26-44.

Movimprese. 2012. "Infocamere: la Società Informatica delle Camere di CommercioItaliane." (online resource center for the ItalianChambers of Commerce). http://www.infocamere.it/movimprese, Accessed November 18, 2017.

Pant, D. R. 2005. “A Place Brand Strategy for the Republic of Armenia: 'Quality of Context' and 'Sustainability' as Competitive Advantage.” JOURNAL OF PLACE BRANDING 1(3):273-82.

Paolazzi, L., and F. Trau' (eds.). 2012. SCENARI INDUSTRIALI (No. 3, June '12), CentroStudi Confindustria (Confederation of Italian Industries), Rome (Italy).

Ricks, D.A. 2006. Blunders in International Business, Blackwell Publishing, Malden (Ma.), USA

Schwab, K., Sala-i-Martín, X., Samans, R. \& Blanke, J. 2016. The Global Competitiveness Report 20162017, World Economic Forum, Geneva (Switzerland).

Schultz, M. 1995. On Studying Organizational Cultures: Diagnosis and Understanding, Berlin, N.Y., Walter De Gruyter, Berlin/New York. 